\title{
Does the Use of Imported Intermediates Increase Productivity? Plant-Level Evidence
}

\author{
Hiroyuki Kasahara and Joel Rodrigue* \\ Department of Economics, Queen's University \\ Preliminary and Incomplete
}

January 31,2004

\begin{abstract}
This paper examines whether importing intermediate goods improves plant performance. While addressing the issue of simultaneity of a productivity shock and decisions to import intermediates, we estimate the impact of the use of foreign intermediates on plants' productivity using plant-level Chilean manufacturing panel data. We found that the switching from being a non-importer to being an importer of foreign intermediates can improve productivity by 3.4 to 22.5 percent.
\end{abstract}

Key Words: productivity, imported intermediates, plant-level JEL: F10, D21, D24

\section{Introduction}

International trade is one of the primary avenues for the diffusion and adoption of new technologies worldwide. This is particularly true and important for developing nations where it is believed that importing new technologies is a significant source of productivity and economic growth. Through adoption and imitation of imported technologies, countries can take advantage of research and development (R\&D) abroad to improve the efficiency of domestic production.

*E-mail: kasahara@qed.econ.queensu.ca and rodrigue@qed.econ.queensu.ca 
The previous empirical work using aggregate cross-country data show that importing intermediate goods that embody R\&D from an industrial country can significantly boost a country's productivity (c.f., Coe and Helpman, 1995; Coe, Helpman and Hoffmaister, 1997). Countries that are more open to trade benefit more from foreign R\&D because they are better able to access improvements in technology by importing intermediate goods. ${ }^{1}$ Aggregated data, however, does not capture heterogeneity across different plants in the economy. As empirically shown by Baily, Hulten, and David (1992), to understand changes in aggregate productivity levels it is vital to examine plant-level changes. Furthermore, recent developments in trade theory suggest that understanding the plant-level response to trade policy is a crucial factor in understanding its impact on aggregate productivity (e.g., Melitz, 2003; Bernard, Eaton, Jensen and Kortum, 2003). Yet, few previous studies have empirically examined the impact of importing intermediate goods on productivity at plant level. ${ }^{2}$

The goal of this paper is to test whether the use of foreign intermediate goods increases plant productivity, using a detailed panel data set on Chilean manufacturing plants from 1979-1986. The data set captures plant heterogeneity in terms of importing decisions: some plants import most of the intermediate goods, others do not at all. While importers are larger and more productive than non-importers in the data, the direction of causality between importing foreign intermediates and plant's performance is not clear. Does the use of foreign intermediate goods per se increase productivity? Or, do inherently high productivity plants tend to use foreign intermediate goods? To answer these questions, we estimate the impact of the use of imported intermediates on plant's productivity while addressing the important issue of simultaneity of a productivity shock and decisions to import intermediates. Specifically, utilizing the panel nature of the data set, we employ the three alternatives to OLS estimator: (i) The WithinGroups Estimator, (ii) The System GMM Estimator (c.f., Blundell and Bond, 1998), and (iii) The Proxy Estimator (c.f., Olley and Pakes, 1996; Levinsohn and Petrin, 2003).

The results from our analysis clearly indicate substantial positive impact of the use of imported intermediates on plant productivity. The Within-Groups estimates show that the use of imported intermediates per se increases plant's productivity by $3.4-3.9$ percent. The point

\footnotetext{
${ }^{1}$ Keller (2001) provides the industry-level empirical evidence for the role of R\&D spillovers through imports.

${ }^{2}$ On the other hand, there is a growing literature on the impact of exporting on firm performance. The typical finding is that, while good firms become exporters, becoming exporters do not necessarily improve firm performance (c.f., Clerides, Lach, and Tybout, 1998; Bernard and Jensen, 1999).
} 
estimates from the System GMM and the Proxy Estimators suggest even larger impact of the use of imported intermediates on productivity: 13.2-22.4 percent. Overall, the empirical analysis in this paper provides strong plant-level evidence for the role of imported intermediates in increasing plant's productivity.

The paper is organized as follows. The next section proceeds to describe the analytical framework used to study the relationship between productivity and imported intermediates. Section 3 outlines the empirical specification, while sections 4 and 5 explain the estimation procedure and data set, respectively. The sixth section presents the results and the seventh concludes.

\section{The Analytical Framework}

Time is discrete. For each period $t$, the $i$ th plant's production, $Y_{i t}$, is given by:

$$
Y_{i t}=e^{\omega_{i t}} K_{i t}^{\beta_{k}} L_{i t}^{\beta_{l}} E_{i t}^{\beta_{e}}\left[\int_{0}^{N\left(d_{i t}\right)} x(j)^{\frac{\gamma-1}{\gamma}} d j\right]^{\frac{\beta_{x} \gamma}{\gamma-1}}
$$

where $\omega_{i t}$ represents a serially correlated productivity shock, $L_{i t}$ is labor input, $K_{i t}$ is capital input, $E_{i t}$ is energy input, and $X_{i t}$ is a composite input consisting of horizontally differentiated intermediate goods $x(j)$ of variety $j$. The elasticity of substitution between any two material inputs is given by $\gamma>1$. The variable $N\left(d_{i t}\right)$ denotes the range of intermediate inputs which are employed in the $i$ th plant; it is a function of a plant's discrete choice, denoted by $d_{i t}$, to import from abroad or not:

$$
N\left(d_{i t}\right)=\left\{\begin{array}{cc}
N_{h, t}, & \text { for } d_{i t}=0 \\
N_{f, t}, & \text { for } d_{i t}=1
\end{array}\right.
$$

where $N_{h, t}$ is the range of intermediate inputs produced in this country and $N_{f, t}$ is the range of intermediate inputs available in the world. There are a range of intermediate inputs that are not produced domestically in this country but are produced in foreign countries and thus available through imports. Therefore, $N_{f, t}>N_{h, t}$. The ratio

$$
\frac{N_{f, t}}{N_{h, t}} \geq 1
$$

represents the technological gap in ability to produce a variety of intermediate goods between the rest of the world and this country. 
Consider the equilibrium in which all intermediate goods are symmetrically produced at level $\bar{x}$. Substituting $x(j)=\bar{x}$ into equation (1) leads to

$$
Y_{i t}=e^{\omega_{i t}} N\left(d_{i t}\right)^{\frac{\beta_{x}}{\gamma-1}} K_{i t}^{\beta_{k}} L_{i t}^{\beta_{l}} E_{i t}^{\beta_{e}} X_{i t}^{\beta_{x}},
$$

where $X_{i t}=N\left(d_{i t}\right) \bar{x}$.

Total factor productivity (TFP) is defined as $A_{i t}=\frac{Y_{i t}}{K_{i t}^{\beta_{k}} L_{i t}^{\beta_{l}} E_{i t}^{\beta_{e}} X_{i t}^{\beta_{x}}}$. Then, from equation (2),

$$
\ln A\left(d_{i t}, \omega\right)=\frac{\beta_{x}}{\gamma-1} \ln \left(N\left(d_{i t}\right)\right)+\omega_{i t}
$$

This equation indicates that productivity is positively related to the range of employed intermediate inputs. In the view of equation (2), plants importing intermediate inputs from abroad employ a larger variety of intermediate inputs and hence exhibit higher productivity than those employing domestic intermediate inputs only; for example, had there been no difference in the value of $\omega$ across plants, then $\ln A(1, \omega)-\ln A(0, \omega)=\frac{\beta_{x}}{\gamma-1} \ln (N(1) / N(0))>0$.

\section{Econometric Specification}

We examine whether the use of imported intermediates leads to a higher productivity by estimating the following Cobb-Douglas production function augmented by the term representing the use of imported intermediates:

$$
y_{i t}=\beta_{0}+\beta_{k} k_{i t}+\beta_{l} l_{i t}+\beta_{e} e_{i t}+\beta_{x} x_{i t}+\beta_{d} d_{i t}+\omega_{i t}+\eta_{i t},
$$

where $y_{i t}=\ln Y_{i t}, k_{i t}=\ln K_{i t}, l_{i t}=\ln L_{i t}, e_{i t}=\ln E_{i t}$, and $x_{i t}=\ln X_{i t}$. A plant's discrete choice to import from abroad is denoted by $d_{i t}$. $\omega_{i t}$ is a serially correlated shock and $\eta_{i t}$ is an i.i.d. shock.

We examine whether the use of imported intermediates leads to higher productivity by testing whether $\beta_{d}>0$. A positive estimate of $\beta_{d}$ provides plant-level evidence for $\mathrm{R} \& \mathrm{D}$ spillovers through trade in intermediate goods. It suggests that plants using the imported intermediates close the technological gap between the home country and the rest of the world, i.e., $\frac{\beta_{x}}{\gamma-1} \ln (N(1) / N(0))$, and hence achieve a higher productivity relative to those only using domestic intermediates.

The degree of the technological gap may differ across plants, for instance, if they produce different products. In fact, among plants that are using imported intermediates, we observe 
substantial differences in the ratios of imported intermediates to total intermediates. Assuming that all intermediate goods are symmetrically produced at level $\bar{x}$ and that plants only import a variety of intermediate goods that are not available in domestic market, we may use the ratio of total intermediates to domestic intermediates as a measurement of the technological gap between world and domestic technology since

$$
\frac{X_{i t}}{X_{i t}^{h}}=\frac{N(1) \bar{x}}{N(0) \bar{x}}=\frac{N(1)}{N(0)}
$$

where $X_{i t}$ is total intermediates and $X_{i t}^{h}$ is domestic intermediates.

We examine whether a larger technological gap leads to higher productivity conditional on the use of imported intermediates by considering the following alternative specification:

$$
y_{i t}=\beta_{0}+\beta_{k} k_{i t}+\beta_{l} l_{i t}+\beta_{e} e_{i t}+\beta_{x} x_{i t}+\beta_{n} n_{i t}+\omega_{i t}+\eta_{i t},
$$

where

$$
n_{i t}=\ln \frac{X_{i t}}{X_{i t}^{h}}
$$

From the estimate of $\beta_{n}$ and $\beta_{x}$, we may compute the elasticity of substitution across different varieties of intermediate goods, denoted by $\gamma$, using $\beta_{n}=\frac{\beta_{x}}{\gamma-1}$.

\section{Estimation}

One of the main econometric issues in estimating the equations (3)-(4) is the simultaneity of a productivity shock $\omega_{i t}+\eta_{i t}$ and input decisions, including the decision to use imported intermediates. ${ }^{3}$ For example, if inputs are chosen on the basis of the productivity shocks, a plant with a higher productivity shock may use more inputs; since the regressors are correlated with the error term, one of the conditions for unbiased and consistent estimation by ordinary least squares (OLS) is violated. To address the simultaneity issue, we consider the following three alternatives to the OLS estimator: (i) The Within-Groups Estimator, (ii) The System GMM Estimator (c.f., Blundell and Bond, 1998), and (iii) The Proxy Estimator (c.f., Olley and Pakes, 1996; Levinsohn and Petrin, 2003).

\footnotetext{
${ }^{3}$ The selection due to endogenous exit decisions is another important issue. We are planning to examine the issue of the self-selection with the unbalanced panel data set in the future by using the framework developed by Olley and Pakes (1996) in the context of the input proxy estimator of Levinsohn and Petrin.
} 
The within-groups estimator only uses the within-plant variation so that it is robust against the simultaneity arising from the correlation between an unobserved plant-specific productivity shock and inputs. For short panels, however, the between-plant variation often plays an important role in identifying the parameters; this is especially true for coefficients of capital and imported intermediates where the within-plant variation is much less than the between-plant variation due to the slow adjustment of capital and the persistence in the import status over time. The within-estimator may lead to imprecise estimates especially for capital and imported intermediates.

To deal with the issue of simultaneity in panel data, Blundell and Bond $(1998,2000)$ propose the system GMM estimator by extending the first differenced GMM estimator (c.f., Arellano and Bond, 1991). Consider the equation (3) with the following additional structure on $\omega_{i t}$ :

$$
\begin{aligned}
\omega_{i t} & =\xi_{t}+\alpha_{i}+v_{i t}, \\
v_{i t} & =\rho v_{i, t-1}+\zeta_{i t},
\end{aligned}
$$

where $\xi_{t}$ is a year-specific effect, $\alpha_{i}$ is a plant-specific effect, $v_{i t}$ is $\operatorname{AR}(1)$ productivity shock with $|\rho|<1$, and $\zeta_{i t}$ is $\operatorname{MA}(0)$. The system GMM estimator is based on two sets of moment conditions. The first set of the moment conditions comes from the first differenced equations (to eliminate the plant-specific effect) with lagged levels of the variables as instruments (c.f., Arellano and Bond, 1991). The first-differenced GMM estimator based only on these moment conditions may have poor finite sample properties due to weak instruments. Blundell and Bond (1998) find that exploiting the additional moment conditions implied by the initial conditions restriction under stationarity may lead to dramatic reductions in finite sample bias; these additional moment conditions are based on the level equations with lagged differences of the variable as instruments. ${ }^{4}$ We employ the system GMM estimator that uses both sets of moment conditions to estimate the parameters. The appendix provides a detailed discussion of the estimation procedure and moment conditions.

Levinsohn and Petrin (2003) show how to use intermediate inputs to control for correlation between inputs and an unobserved productivity shock. ${ }^{5}$ We apply the Levinsohn and Petrin

\footnotetext{
${ }^{4}$ Recently, however, some researchers found that even the system GMM estimator may lead to imprecise and possibly biased estimates due to weak instruments. For example, see Griliches and Mairesse (1998), Mulkay, Hall, and Mairesse (2000), and Levinsohn and Petrin (2003).

${ }^{5}$ Their estimator is developed based on the investment proxy estimator of Olley and Pakes (1996). In the
} 
estimator to the production function (3) as follows. Suppose that capital $k_{i t}$ and the import decision $d_{i t}$ are the state variables but $l_{i t}, x_{i t}$, and $e_{i t}$ are freely variable inputs. ${ }^{6}$ Assume that a plant does not observe $\eta_{i t}$ at the time of material input decisions. ${ }^{7}$ Then, the material's demand function is given as $x_{i t}=x_{t}\left(\omega_{i t}, k_{i t}, d_{i t}\right)$, where the function $x_{t}(\cdot)$ is time-dependent, reflecting its dependence on time-specific common shocks in productivity and prices. Assuming that $x_{t}(\cdot)$ is strictly increasing in $\omega_{i t}$, we can invert this function to obtain the productivity shock $\omega_{i t}$ as a function of $\left(x_{i t}, k_{i t}, d_{i t}\right): \omega_{i t}=\omega_{t}\left(x_{i t}, k_{i t}, d_{i t}\right)$. Replacing $\omega_{t}\left(x_{i t}, k_{i t}, d_{i t}\right)$ for $\omega_{i t}$ in the equation (3) leads to a partial linear function:

$$
y_{i t}=\beta_{l} l_{i t}+\beta_{e} e_{i t}+\phi_{t}\left(x_{i t}, k_{i t}, d_{i t}\right)+\eta_{i t},
$$

where

$$
\phi_{t}\left(x_{i t}, k_{i t}, d_{i t}\right)=\beta_{0}+\beta_{k} k_{i t}+\beta_{x} x_{i t}+\beta_{d} d_{i t}+\omega_{t}\left(x_{i t}, k_{i t}, d_{i t}\right) .
$$

In the first stage, we obtain the consistent estimates of $\beta_{l}$ and $\beta_{e}$. By subtracting the expectation of (6) conditional on $\left(x_{i t}, k_{i t}, d_{i t}\right)$ from (6), we obtain

$$
y_{i t}-E\left(y_{i t} \mid x_{i t}, k_{i t}, d_{i t}\right)=\beta_{l}\left(l_{i t}-E\left(l_{i t} \mid x_{i t}, k_{i t}, d_{i t}\right)\right)+\beta_{e}\left(e_{i t}-E\left(e_{i t} \mid x_{i t}, k_{i t}, d_{i t}\right)\right)+\eta_{i t} .
$$

We first consistently estimate the conditional expectations, $E\left(y_{i t} \mid x_{i t}, k_{i t}, d_{i t}\right), E\left(l_{i t} \mid x_{i t}, k_{i t}, d_{i t}\right)$, and $E\left(e_{i t} \mid x_{i t}, k_{i t}, d_{i t}\right)$ by the OLS regressions of $y_{i t}, l_{i t}$ and $e_{i t}$, respectively, on the power series of $\left(x_{i t}, k_{i t}, d_{i t}\right){ }^{8}$ Using the estimates of the conditional expectations in place of the actual conditional expectations in (7), we estimate $\beta_{l}$ and $\beta_{e}$ by OLS with no-intercept. Denote the estimates by $\hat{\beta}_{l}$ and $\hat{\beta}_{e}$. Note that $\beta_{k}, \beta_{x}$, and $\beta_{d}$ are not identified in the first stage.

In the second stage, define the innovations in productivity conditional on the last year's productivity as:

$$
\nu_{i t}=\omega_{i t}-E_{t}\left[\omega_{i t} \mid \omega_{i, t-1}\right]
$$

Chilean data, there are a substantial number of zero investment observations (perhaps due to the presence of fixed investment cost). For these observations, the investment proxy estimator of Olley and Pakes can not be used because they do not satisfy the monotonicity condition (and thus the investment function is not invertible with respect to shocks). Given this feature of the Chilean data, we choose to use the Levinsohn and Petrin intermediate proxy estimator rather than the Olley and Pakes investment proxy estimator.

${ }^{6}$ Material import $d_{i t}$ is the state variable, for example, if there is a sunk cost to start importing intermediates.

${ }^{7}$ This is not a strong assumption since any observable component of productivity shocks can be included in $\omega_{i t}$.

${ }^{8}$ The results presented in this paper use a fourth order polynomial with a full set of interactions to approximate unknown functions. Using a third order polynomial, we got very similar estimates of the coefficients $\left(\beta_{x}, \beta_{k}, \beta_{d}\right)$. 
For each candidate parameter vector $\beta^{*}=\left(\beta_{x}^{*}, \beta_{k}^{*}, \beta_{d}^{*}\right)$, we may compute an estimate for the residual as follows:

$$
\left(\nu_{i t} \hat{+} \eta_{i t}\right)\left(\beta^{*}\right)=y_{i t}-\hat{\beta}_{l} l_{i t}-\hat{\beta}_{e} e_{i t}-\beta_{k}^{*} k_{i t}-\beta_{x}^{*} x_{i t}-\beta_{d}^{*} d_{i t}-E\left[\omega_{i t} \mid \hat{\omega}{ }_{i, t-1}\right]
$$

where $E\left[\omega_{i t} \mid \hat{\omega}_{i, t-1}\right]$ is the estimate of conditional expectation of $\omega_{i t}$ given $\omega_{i, t-1}$. Here, $E\left[\omega_{i t} \mid \hat{\omega}{ }_{i, t-1}\right]$ is obtained by the year-by-year OLS regression of $\left(\omega_{i t} \hat{+} \eta_{i t}\right)\left(\beta^{*}\right) \equiv y_{i t}-\hat{\beta}_{l} l_{i t}-\hat{\beta}_{e} e_{i t}-\beta_{k}^{*} k_{i t}-$ $\beta_{x}^{*} x_{i t}-\beta_{d}^{*} d_{i t}$ on the power series of $\hat{\omega}_{i, t-1}\left(\beta^{*}\right) \equiv \hat{\phi}_{t-1}\left(x_{i, t-1}, k_{i, t-1}, d_{i, t-1}\right)-\beta_{k}^{*} k_{i, t-1}-\beta_{x}^{*} x_{i, t-1}-$ $\beta_{d}^{*} d_{i, t-1}$, where $\hat{\phi}_{t}(\cdot)$ is the estimate of $\phi_{t}(\cdot)$ obtained by the year-by-year OLS regressions of $y_{i t}-\hat{\beta}_{l} l_{i t}-\hat{\beta}_{e} e_{i t}$ on the power series of $\left(x_{i t}, k_{i t}, d_{i t}\right)$ as implied by equation (6).

We estimate the parameters $\left(\beta_{x}, \beta_{k}, \beta_{d}\right)$ by minimizing the GMM criterion function $Q\left(\beta^{*}\right)=$ $\min _{\beta^{*}} \sum_{h=1}^{7}\left[\sum_{i=1}^{N} \sum_{t=1}^{T}\left(\nu_{i t} \hat{+} \eta_{i t}\right)\left(\beta^{*}\right) Z_{i t, h}\right]^{2}$, where $\left(\nu_{i t} \hat{+} \eta_{i t}\right)\left(\beta^{*}\right)$ is given by $(8), Z_{i t, h}$ is the $h^{t h}$ element of the instrument vector $Z_{i t}=\left(k_{i t}, d_{i t}, k_{i, t-1}, l_{i, t-1}, x_{i, t-1}, e_{i, t-1}, d_{i, t-1}\right) .{ }^{9}$ There are four over-identifying conditions. The standard errors are obtained by the bootstrap. ${ }^{10}$

\section{Data}

The data set is based on a census of Chilean manufacturing plants by Chile's Instituto Nacional de Estadistica (INE) that has been used in previous empirical studies (e.g., Lui, 1993; Pavcnik, 1999; Levinsohn and Petrin, 2003). We focus our attention on the balanced panel data set that consists of the collection of plants present for the whole sample period of 1979-1986. ${ }^{11}$ Other sample selection criteria are the following. We exclude plants for which any of the data for investment, capital stocks, domestic intermediates, and imported intermediates are not available. In particular, plants that do not report book values of their capital stocks in any year are excluded since constructing capital stocks for these plants is impossible. After cleaning the data, the balanced panel data set contains 2066 plants for the period of 1979-1986.

Table 1 reports descriptive statistics for variables in our regression analysis. Out of 2066

\footnotetext{
${ }^{9}$ It is assumed that $k_{i t}$ and $d_{i t}$ are predetermined so that capital and import decisions do not respond to $\nu_{i t}$ and $\eta_{i t}$.

${ }^{10}$ Assuming that each set of plant-level observations $\mathbf{x}_{\mathbf{i}} \equiv\left\{y_{i t}, k_{i t}, l_{i t}, x_{i t}, e_{i t}, d_{i t}\right\}_{t=0}^{T}$ is independently and identically distributed across plants, we draw a bootstrap sample of size $N$ with replacement from the original sample $\left(\mathbf{x}_{1}, \mathbf{x}_{\mathbf{2}}, \ldots, \mathbf{x}_{\mathbf{N}}\right)$. We generate $B$ independent bootstrap samples and estimate the parameters for each sample using the recentered moment conditions (c.f., Horowitz, 2001). The bootstrap standard errors are then computed based on the B sets of parameter estimates.

${ }^{11}$ We are also planning to examine the unbalanced panel data set in the future.
} 
Table 1: Descriptive Statistics

\begin{tabular}{c|cccccccc}
\hline \hline & & & & & Interme- & Import & Output/ & No. of \\
& Output & Capital & Labour & Energy & diates & Ratios & Workers & Plants \\
\hline All & 164.8 & 62.5 & 62.8 & 4.3 & 105.8 & 0.080 & 1.42 & 2066 \\
Plants & $(1171.8)$ & $(440.4)$ & $(118.5)$ & $(32.9)$ & $(1116.6)$ & $(0.185)$ & $(2.56)$ & - \\
\hline Importing & 694.8 & 282.9 & 172.4 & 14.3 & 431.2 & 0.362 & 3.06 & 265 \\
Plants & $(2866.9)$ & $(1134.1)$ & $(234.6)$ & $(61.6)$ & $(2458.7)$ & $(0.248)$ & $(5.22)$ & - \\
\hline Non-Importing & 33.2 & 10.8 & 30.3 & 1.2 & 19.4 & - & 0.86 & 1122 \\
Plants & $(114.8)$ & $(89.3)$ & $(39.8)$ & $(14.5)$ & $(56.8)$ & - & $(0.84)$ & - \\
\hline
\end{tabular}

Notes: Standard errors are in parentheses. "Importing Plants" are plants that continuously imported foreign intermediates for 1979-1986. "Non-Importing Plants" are plants that never imported foreign intermediates for 1979-1986. "Output," "Capital," "Energy," and "Intermediates" are measured in millions of 1980 pesos. "Labor" is the number of workers. "Import Ratios" is the ratio of imported intermediate materials to total intermediate materials.

plants, 265 plants $(12.8 \%)$ continuously import foreign intermediates throughout the sample period (i.e., "Importing Plants" in Table 1), while 1122 plants (54.3\%) are "Non-Importing Plants" that never import intermediates from abroad. This suggests that plant import status is persistent over time. There are, nevertheless, a substantial fraction (32.9\%) of plants that switch between importing and not importing over the period. This within-plant variation of import statuses is an important source of identification of the import variable coefficient, especially for Within-Groups and GMM estimators. A comparison between "Importing Plants" and 'Non-Importing Plants" in Table 1 reveals the substantial differences between the two types of plants. Importing plants are substantially larger and have higher labor productivity, although the direction of causality is not clear.

We now describe the variables used in our regression analysis. The variable $y_{i t}$ is the logarithm of total sales, adjusted for changes in inventories, deflated by a 3-digit industry output deflator. The variable $l_{i t}$ is the logarithm of the average number of workers. The variable $k_{i t}$ is the logarithm of the capital stock in the beginning of year $t$ so that investment in year $t$ is not included in its measurement. The capital stock is constructed from the 1980 book value of capital (the 1981 book value if the 1980 book value is not available), including machinery and equipment, vehicles, and buildings, using perpetual inventory method. ${ }^{12}$ The variable $e_{i t}$ is the

\footnotetext{
${ }^{12}$ Since the reported book values are evaluated at the end of year $t$, the book values of capital in machinery and equipment, and vehicles, are deflated by the (geometric) average deflator of machinery and equipment for years $\mathrm{t}$ and $t+1$. The average deflator of buildings is used to deflate the book values of capital in buildings. Depreciation rates are set to $5 \%$ for buildings, $10 \%$ for machinery and equipment, and $20 \%$ for vehicles. Some plants did not
} 
logarithm of the total purchased value of various types of fuels, including electricity, coal, coke, petroleum, diesel, and liquid gas, deflated by a 3-digit industry fuels deflator. The variable $X_{i t}^{h}$ is real value of domestically produced materials constructed as the total purchased values of materials less the purchased values of imported materials, deflated by a 3 -digit industry materials deflator. Real purchased value of imported materials, denoted by $X_{i t}^{f}$, is the total purchased values of imported materials deflated by import price index. Real value of total intermediate materials, denoted by $X_{i t}$, is the sum of $X_{i t}^{h}$ and $X_{i t}^{f}$. The variable $x_{i t}$ is the logarithm of $X_{i t}$. The variable $d_{i t}$ is equal to one if $X_{i t}^{f}>0$, and zero otherwise. The variable $n_{i t}$ is the logarithm of the ratio of $X_{i t}$ to $X_{i t}^{h}$.

\section{Results}

Table 2 presents the results from OLS, the Within-Groups estimator, the system GMM estimator and the Levinsohn and Petrin estimator using the discrete choice import variable. For OLS, Within-Group, and system GMM, we present the cases of both serially uncorrelated productivity shocks and AR(1) shocks. ${ }^{13}$ While columns (1), (3), and (5) report the estimates under the assumption of serially uncorrelated productivity shocks, columns (2), (4), and (6) report the estimates under the assumption of $\mathrm{AR}(1)$ productivity shocks. The appendix provides the details of estimation procedures.

The most important finding is the significance and large size of the discrete import variable coefficient across different estimators. As shown in columns (1)-(2) of Table 2, the estimated coefficients of the discrete import variable are positive and significant. The OLS point estimate under the assumption of $\mathrm{AR}(1)$ productivity shock in column (2) imply that a plant only using domestic intermediates can increase its productivity by 13 percent if it starts importing intermediates. The OLS estimate is, however, likely to be biased due to correlation between an unobserved plant productivity shock and inputs. The within-estimator is robust against the simultaneity between a permanent plant-specific shock and input decisions. Columns (3)-(4) of Table 2 demonstrate that although estimate of $\beta_{d}$ is considerably smaller using the within-

report the book values of capital in either 1980 or 1981. Since it is not possible to construct capital stock without these reports, the plants missing their book values of capital were excluded from the sample.

${ }^{13}$ To estimate the model with $\mathrm{AR}(1)$ shocks, we first estimate the unrestricted parameter vector of a dynamic common factor representation, and then obtain the restricted parameter vector using minimum distance. See the appendix for the system GMM estimator. 
Table 2: Discrete Choice Import Variable

\begin{tabular}{cccccccc}
\hline \hline \multirow{2}{*}{ Variable } & \multicolumn{2}{c}{ OLS } & \multicolumn{2}{c}{ Within } & \multicolumn{2}{c}{ GMM } & $\begin{array}{c}\text { Levinsohn } \\
\text { Groups }\end{array}$ \\
& $(1)$ & $(2)$ & $(3)$ & $(4)$ & $(5)$ & $(6)$ & $(7)$ \\
\hline$k_{t}$ & 0.0752 & 0.0762 & 0.0193 & 0.0076 & 0.0798 & 0.0787 & 0.0314 \\
& $(0.0032)$ & $(0.0040)$ & $(0.0065)$ & $(0.0073)$ & $(0.0209)$ & $(0.0627)$ & $(0.0118)$ \\
$l_{t}$ & 0.2759 & 0.2641 & 0.2482 & 0.2188 & 0.2034 & 0.3565 & 0.2511 \\
& $(0.0065)$ & $(0.0084)$ & $(0.0127)$ & $(0.0138)$ & $(0.0380)$ & $(0.1127)$ & $(0.0120)$ \\
$e_{t}$ & 0.0572 & 0.0650 & 0.0651 & 0.0704 & 0.0590 & 0.1518 & 0.0449 \\
& $(0.0031)$ & $(0.0036)$ & $(0.0049)$ & $(0.0053)$ & $(0.0202)$ & $(0.0613)$ & $(0.0065)$ \\
$x_{t}$ & 0.6593 & 0.6665 & 0.5859 & 0.5850 & 0.6948 & 0.5233 & 0.7704 \\
& $(0.0050)$ & $(0.0071)$ & $(0.0114)$ & $(0.0131)$ & $(0.0213)$ & $(0.0545)$ & $(0.0194)$ \\
$d_{t}$ & 0.1894 & 0.1286 & 0.0344 & 0.0389 & 0.2243 & 0.1322 & 0.1641 \\
& $(0.0074)$ & $(0.0082)$ & $(0.0087)$ & $(0.0092)$ & $(0.0499)$ & $(0.1186)$ & $0.0177)$ \\
$y_{t-1}$ & & 0.4058 & & 0.1931 & & 0.5721 & \\
& & $(0.0219)$ & & $(0.0210)$ & & $(0.0598)$ & \\
\hline
\end{tabular}

Notes: Standard errors are in parentheses.

estimator relative to OLS, at 3.4-3.9 percent, it is still positive and significant.

While the within-estimator controls for correlation between inputs and a permanent shock, it does not address the simultaneity between inputs and the persistent shock that varies withinplant over time. To correct for such simultaneity in panel data, we further provide the results from two alternative estimators: the system GMM estimator and the Levinsohn and Petrin input proxy estimator. The system GMM estimates in columns (5)-(6) of Table 2 also indicate that imports have a strong, positive effect on plant productivity. ${ }^{14}$ The $\operatorname{AR}(1)$ model once again finds a 13 percent increase in productivity from a switch to imports although the estimates are not as significant. Finally, column (7) of Table 2 provides the result of the Levinsohn and Petrin estimator which controls for correlation between inputs and an unobserved productivity shock by using intermediate inputs as proxies for unobserved productivity shocks. The results of the Levinsohn and Petrin estimator indicates a 16 percent increase in productivity from a switch to imported intermediates.

Table 3 presents estimates using the continuous measure of import usage. The coefficients

\footnotetext{
${ }^{14}$ The results for system GMM estimation in Table 2 use a lag length of 2 and larger for instruments. We also estimated using a lag lengths of 3 and larger for instruments, which are valid in the presence of measurement errors, and found that the estimates and the standard errors of the coefficient of import variables are similar to those presented in columns (5)-(6) of Table 2.
} 
Table 3: Continous Variable: $n=\ln X / X^{h}$

\begin{tabular}{cccccccc}
\hline \hline \multirow{2}{*}{ Variable } & \multicolumn{2}{c}{ OLS } & \multicolumn{2}{c}{ Within } & \multicolumn{2}{c}{ GMM } & Levinsohn \\
& $(1)$ & $(2)$ & $(3)$ & $(4)$ & $(5)$ & $(6)$ & $(7)$ \\
\hline$k_{t}$ & 0.0797 & 0.0778 & 0.0196 & 0.0080 & 0.0986 & 0.1103 & 0.0292 \\
& $(0.0032)$ & $(0.0040)$ & $(0.0064)$ & $(0.0073)$ & $(0.0199)$ & $(0.0606)$ & $(0.0106)$ \\
$l_{t}$ & 0.2917 & 0.2669 & 0.2493 & 0.2193 & 0.2019 & 0.3332 & 0.2580 \\
& $(0.0066)$ & $(0.0083)$ & $(0.0127)$ & $(0.0137)$ & $(0.0372)$ & $(0.1097)$ & $(0.0118)$ \\
$e_{t}$ & 0.0561 & 0.0649 & 0.0652 & 0.0705 & 0.0361 & 0.1339 & 0.0457 \\
& $(0.0031)$ & $(0.0036)$ & $(0.0049)$ & $(0.0053)$ & $(0.0205)$ & $(0.0630)$ & $(0.006)$ \\
$x_{t}$ & 0.6635 & 0.6756 & 0.5870 & 0.5857 & 0.7120 & 0.5475 & 0.7853 \\
& $(0.0051)$ & $(0.0071)$ & $(0.0114)$ & $(0.0131)$ & $(0.0212)$ & $(0.0577)$ & $(0.0157)$ \\
$n_{t}$ & 0.1559 & 0.1214 & 0.0152 & 0.0210 & 0.1415 & 0.2021 & 0.1433 \\
& $(0.0105)$ & $(0.0095)$ & $(0.0099)$ & $(0.0102)$ & $(0.0549)$ & $(0.1036)$ & $(0.0145)$ \\
$y_{t-1}$ & & 0.3980 & & 0.1936 & & 0.5545 & \\
& & $(0.0215)$ & & $(0.0210)$ & & $(0.0610)$ & \\
Implied $\gamma$ & 5.256 & 6.565 & 39.618 & 28.890 & 6.032 & 3.709 & 6.480 \\
\hline
\end{tabular}

Notes: Standard errors are in parentheses.

for the continuous import variable are significant and of large size across different estimators, indicating the importance of foreign intermediates in explaining productivity differences across plants and over time. The OLS results in columns (1) and (2) suggest decreasing the share of domestic intermediates in total intermediates by 1 percent could lead to a 0.12 to 0.15 percent increase in productivity. The within estimator once again predicts a lower but still positive and significant effect of increasing imported intermediates on productivity. The results from other two alternative estimators that control for the possible correlation between the inputs and productivity shocks also show that imports have a strong, positive effect on productivity. The system GMM estimates in columns (5) and (6) of Table 3 imply that a 1 percent decrease in the share of domestic intermediates in total intermediates could increase productivity between 0.14 and 0.20 percent. Again, the Levinsohn and Petrin estimator supports a substantial impact of an increase in the share of imported intermediates on productivity, finding that a 1 percent decrease in the share of domestic intermediates increases productivity by 0.14 percent.

From the estimates of $\beta_{n}$, we can compute an estimate of the elasticity of substitution, $\gamma$. Using the system GMM estimates with and without serial correlation and the Levinsohn and Petrin estimates we obtain estimates of $\gamma$ of $6.03,3.71$, and 6.48 . These estimates are in line with 
those found by Feenstra (1994) and indicate that there is significant evidence that productivity increases through specialization.

Non-importing plants may improve their productivity by expanding the variety of intermediate goods when they start using imported intermediates. The extent to which the use of imported intermediates increases productivity crucially depends on the technological gap, measured as the ratio of total intermediates to domestic intermediates, $n_{i t}$, among importing plants. We calculate the average of $n_{i t}$ is 0.45 for importing plants, implying that non-importing plants, on average, use only $63.8\left(=e^{-0.45}\right)$ percent of available variety of intermediate goods in the world relative to importing plants. Our estimated coefficient of $n$ using the Levinsohn and Petrin estimator suggests that expanding the variety of intermediates by switching from being a non-importer to an importer of foreign intermediates increases a plant's productivity, on average, by $6.4(=0.143 \times 0.45)$ percent.

\section{Conclusion}

The results in this paper demonstrate significant plant-level evidence that imported intermediates improve a plant's productivity. We found that by switching from being a non-importer to an importer of foreign intermediates a plant can improve productivity by 3.4 to 22.5 percent. Intermediate imports, therefore, allow plants to adopt technology from abroad and substantially benefit from foreign research and development. This result alone is important for both government policy and plant production strategy.

The empirical findings of this paper shed new light on the issue of how trade policy affects aggregate productivity and suggest directions for future research. Recent developments in trade theory, focusing on heterogeneous plants, suggest that understanding the plant-level response to trade policy is a crucial factor in understanding its impact on aggregate productivity (e.g., Melitz, 2003; Bernard, Eaton, Jensen and Kortum, 2003). Our results imply that understanding the plant-level import decisions may be particularly important in understanding the impact of trade policy on aggregate productivity. While there is a growing empirical literature on plant-level export decisions (e.g., Roberts and Tybout, 1997; Bernard and Jensen, 1999), few empirical studies have examined the determinants of the plant-level import decisions. Is there a sunk start-up cost for importing intermediates? What is the role of plant characteristics (e.g., past 
experience, labor quality, geographic location) in the import decisions? How are import decisions related to the export decisions at the plant level? These are important research questions we are planning to pursue in our future research.

\section{Appendix}

\section{A.1 The Blundell and Bond System GMM Estimator}

Using a dynamic common factor representation, (3) with (5) can be rewritten as:

$$
\begin{aligned}
y_{i t}= & (1-\rho) \beta_{0}+\beta_{k} k_{i t}-\rho \beta_{k} k_{i, t-1}+\beta_{l} l_{i t}-\rho \beta_{l} l_{i, t-1}+\beta_{e} e_{i t}-\rho \beta_{e} e_{i, t-1}+\beta_{x} x_{i t}-\rho \beta_{x} x_{i, t-1} \\
& +\beta_{d} d_{i t}-\rho \beta_{d} d_{i, t-1}+\rho y_{i, t-1}+\xi_{t}^{*}+\alpha_{i}^{*}+\mu_{i t}
\end{aligned}
$$

where $\xi_{t}^{*}=\xi_{t}-\rho \xi_{t-1}, \alpha_{i}^{*}=(1-\rho) \alpha_{i}$, and $\mu_{i t}=\zeta_{i t}+\eta_{i t}-\rho \eta_{i, t-1}$.

Following Blundell and Bond (2000), we estimate the unrestricted parameter vector of (9) by the one-step GMM and then obtain the restricted parameter vector $\left(\rho, \beta_{0}, \beta_{k}, \beta_{l}, \beta_{e}, \beta_{m}, \beta_{d}\right)$ using minimum distance (c.f., Chamberlain (1982)). The following moment conditions are used:

$$
\begin{aligned}
E\left[z_{i, t-s} \Delta \mu_{i t}\right] & =0 \text { for } s \geq 3, \\
E\left[\Delta z_{i, t-s}\left(\alpha_{i}^{*}+\mu_{i t}\right)\right] & =0 \text { for } s=2,
\end{aligned}
$$

where $z_{i t}=\left(y_{i t}, k_{i t}, l_{i t}, x_{i t}, d_{i t}\right)$ and $\Delta z_{i t}=z_{i t}-z_{i, t-1}$.

\section{References}

[1] Arellano, M., and S.R. Bond (1991) "Some Test of Specification for Panel Data: Monte Carlo Evidence and an Application to Employment Equations," Review of Economic Studies, 58: 277-297.

[2] Baily, Martin N., Hulten, Charles, and Campbell, David (1992) "Productivity Dynamics in Manufacturing Plants," Brookings Papers on Economic Activity: Microeconomics, 67-119.

[3] Bernard, Andrew B. and J. Bradford Jensen (1999) "Exceptional Exporter Performance: Cause, Effect, and or Both?" Journal of International Economics, 47: 1-25. 
[4] Bernard, Andrew B., Jonathan Eaton, J. Bradford Jensen, and Samuel Kortum (2003) "Plants and Productivity in International Trade," American Economic Review, 93(4): 1268-1290.

[5] Blundell, R.W. and S.R. Bond (1998) "Initial Conditions and Moment Restrictions in Dynamic Panel Data Models," Journal of Econometrics, 68: 29-51.

[6] Blundell, R.W. and S.R. Bond (2000) "GMM Estimation with Persistent Panel Data: an Application to Production Functions," Econometric Reviews, 19(3): 321-340.

[7] Chamberlain, G. (1982) "Multivariate Regression Models for Panel Data," Journal of Econometrics, 18: 5-46.

[8] Clerides, Sofronis, Lach, Saul, and James R. Tybout (1998) "Is Learning by Exporting Important? Micro-Dynamic Evidence from Colombia, Mexico, and Morocco," Quarterly Journal of Economics 113: 903-947.

[9] Coe, David T. and Elhanan Helpman (1995) "International R\&D Spillovers," European Economic Review, 39: 859-887.

[10] Coe, David T., Elhanan Helpman, and Alexander W. Hoffmaister (1997) "North-South R\&D Spillovers," Economic Journal, 107: 134-149.

[11] Feenstra, Robert C. (1994) "New Product Varieties and the Measurement of International Prices," American Economic Review, 84(1): 157-177.

[12] Grilicches, Z. and J. Mairesse (1998) "Production Functions: The Search for Identification," in S.Stöm e., Econometrics and Economic Theory in the 20th Century: The Ragnar Frish Centennial Symposium Cambridge, England: Cambridge University Press, pp. 169203.

[13] Grossman, G.M. and E. Helpman (1991) Innovation and Growth in the Global Economy, Cambridge, MA: MIT Press.

[14] Horowitz, Joel L. (2001) "The Bootstrap," in J.J. Heckman and E. Leamer (eds.) Handbook of Econometrics, Vol. 5, Oxford: Elsevier Science, 3159-3228. 
[15] Keller, Wolfgang. (2002) "Trade and the Transmission of Technology," Journal of Economic Growth, (1): 5-24.

[16] Lui, L. (1993) "Entry, Exit, and Learning in the Chilean Manufacturing Sector," Journal of Development Economics, 42: 217-242.

[17] Levinsohn, James and Amil Petrin (2003) "Estimating Production Functions Using Inputs to Control for Unobservables," Review of Economic Studies, 70:317-341.

[18] Marschak, J. and Andrews, W.H. (1994) "Random Simultaneous Equations and the Theory of Production," Econometrica, 12(3,4): 143-205.

[19] Melitz, Mark J.(2003) "The Impact of Trade on Intra-Industry Reallocations and Aggregate Industry Productivity," Econometrica, 71: 1695-1725.

[20] Mulkay, Benoit, Hall, Bronwyn H., and Jacques Mairesse (2000) "Firm Level Investment and R\&D in France and the United States: A Comparison," National Bureau of Eocnomic Research, Working Paper No. 8038.

[21] Olley, S. and Pakes, A. (1996) "The Dynamics of Productivity in the Telecommunications Equipment Industry," Econometrica, 65(1): 292-332.

[22] Pavcnik, Nina (2002) "Trade Liberalization, Exit, and Productivity Improvements: Evidence From Chilean Plants," Review of Economic Studies, 69(1): 245-276.

[23] Roberts, Mark and Tybout, Robert (1997) "Decision to Export in Columbia: An Empirical Model of Entry with Sunk Costs" American Economic Review, 87: 545-564. 